\title{
Jacqueline Cumming
}

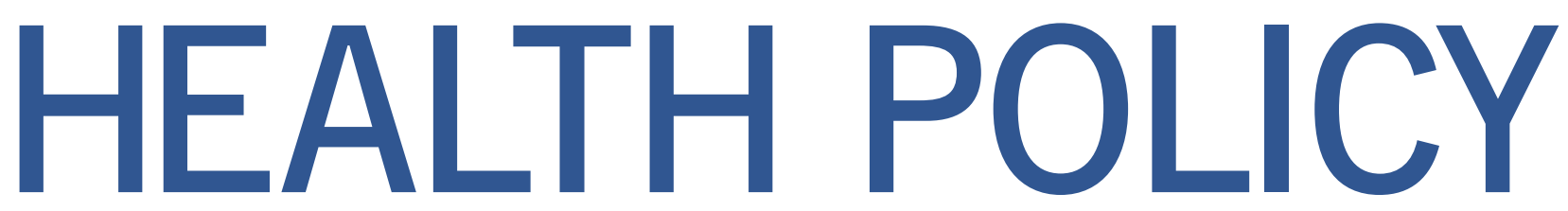

Introduction

Improving health and well-being and promoting equity in outcomes are long-standing goals of New Zealand governments (for example, Department of Health, 1989; King, 2000; Ryall, 2007; Ministry of Health, 2016a, 2016b). ${ }^{1}$ New Zealand's publicly funded health system delivers millions of high-quality services each year to achieve these goals. Our level of expenditure per capita on health care is slightly below the OECD average, but our health care system provides good overall health outcomes for the money we spend (OECD, 2015). Both our life expectancy and health expectancy (the years we live in good health) are increasing, although the former is increasing faster than the latter, leading to an increase in the number of years New Zealanders spend in poorer health; a key challenge is to improve our quality of life as people age (Ministry of Health, 2017a). Sadly, however, there are significant inequities in health, with Māori, Pasifika and lower-income people having poorer health than other New Zealanders (Ministry of Health, 2017a).

Jacqueline Cumming is Director of the Health Services Research Centre and a Professor in the Faculty of Health at Victoria University of Wellington.
Health policy is one of the most challenging for any government. Many more health needs could be met with new funding; indeed, the demand for health care is virtually insatiable. There are significant inequities in health to ameliorate. There are workforce shortages and salary inequities to overcome. There are demands for new technologies. And there are rising demands for services arising from ageing populations and a growing burden from long-term conditions. These factors pressure governments every day to spend more.

This article explores some key questions to ask of potential future governments in relation to health policy in New Zealand. First, I look at issues relating to the health of New Zealanders. Second, I discuss recent health expenditure trends. Third, I turn to focus on how we are doing with respect to primary health care, an area that has been at the forefront of New Zealand health policy debate in recent years. Finally, I draw some overall conclusions.

Improving the health of New Zealanders A first key question is how much government funding is allocated to health care as opposed to other areas. It may well be that key gains in health will come from spending outside the health care vote. New Zealand needs to do better 
in initiatives to reduce poverty, support access to affordable healthy homes, reduce violence and improve education outcomes, especially for specific groups in the population. There is good evidence that spending in such areas can pay off in terms of improving health and potentially reducing the demands on health care services over time (World Health Organization, 2013; Taylor et al. 2016).

A second key question surrounds government priorities within health care. There is a tendency for those issues on the front pages of the newspapers to dominate our thinking. What is often missing, however, is a careful assessment of our current health status and its distribution across the population, and a clear outline of where key priorities lie. Those contesting the election should explain how they intend to tackle our key health concerns, such as mental health issues (including suicide), cancers, cardiovascular disease, diabetes, musculoskeletal conditions, dementia, injuries and oral health (Ministry of Health, 2017a). A number of these concerns have common underlying risk factors, including smoking, poor diet, lack of physical activity and abuse of alcohol and drugs, alongside occupational risks. These are issues that will take sustained attention if we are to reduce their impact over time (World Health Organization, 2013; Taylor et al. 2016).

A third key question relates to inequities in health. In 2012-14, life expectancy at birth was 77.1 years for Māori females and 73.0 years for Māori males, compared with 83.9 years for nonMāori females and 80.3 years for nonMāori males. It was 78.7 years for Pasifika females and 74.5 years for Pasifika males (Statistics New Zealand, 2015). With respect to amenable mortality (premature death that could be avoided, given effective and timely health care), Māori have rates 2.7 times higher and Pasifika peoples have rates 2.4 times higher than the non-Māori, non-Pasifika population (Ministry of Health, 2017a). We should be challenging potential future governments to be clear on what they intend to do to tackle such inequities. In recent years there appears to have been little clear policy aimed at reducing such inequities.

Figure 1: New Zealand Health Expenditure 1993-2018 \$m

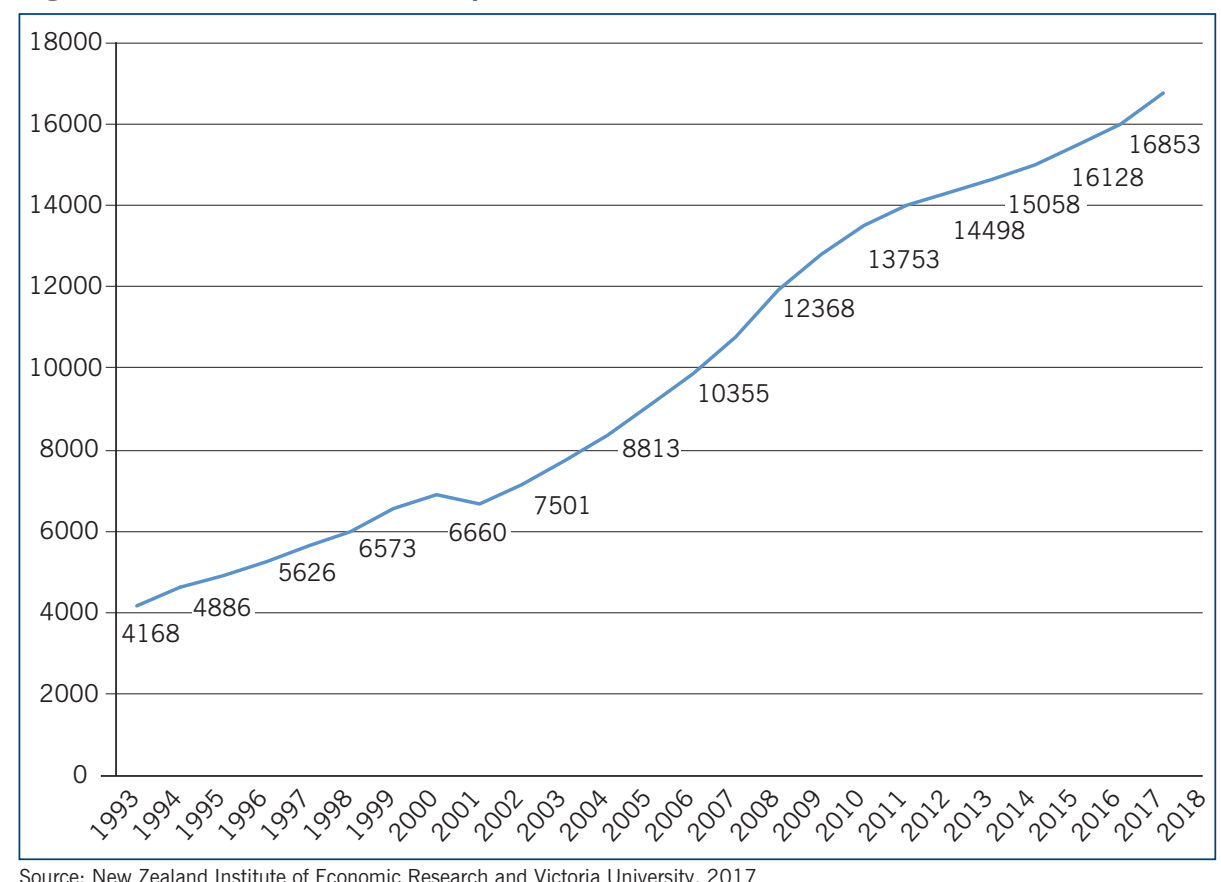

Figure 2: Real \$NZ Per Capita Health Expenditure 1993-2018

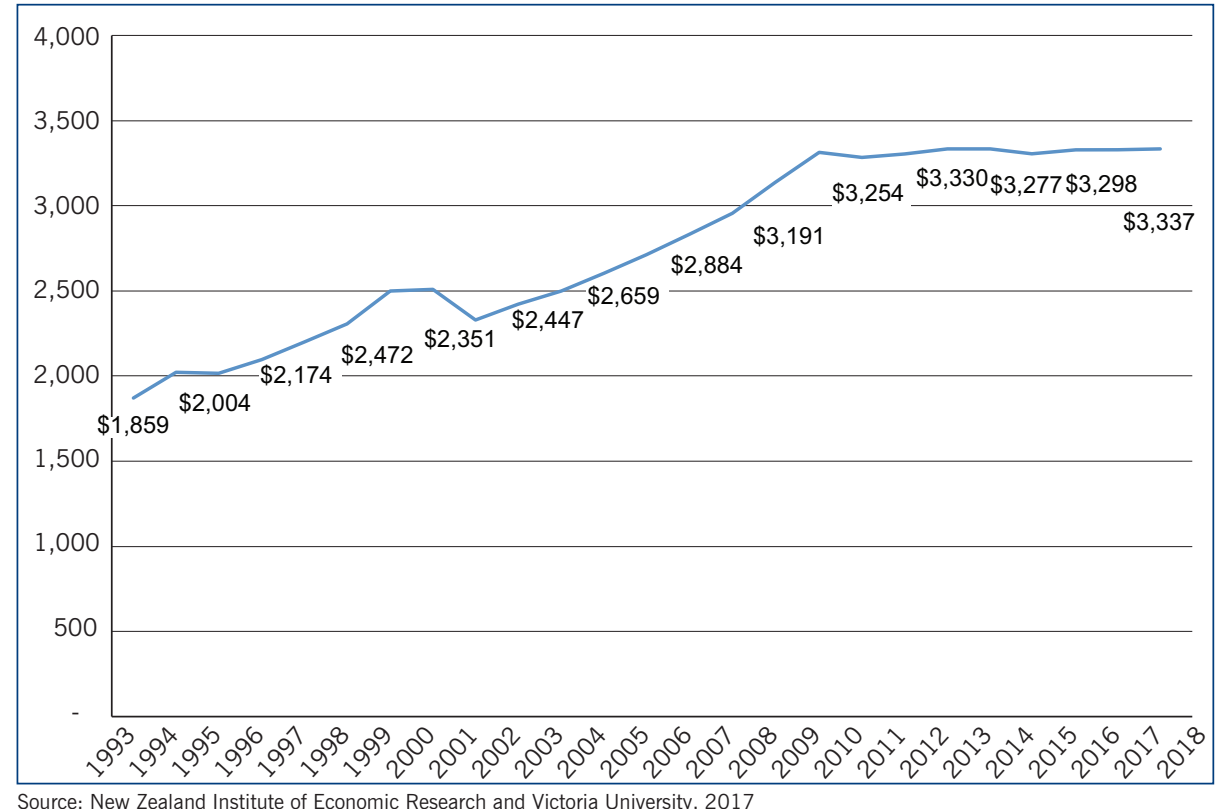

Source: New Zealand Institute of Economic Research and Victoria University, 2017

Trends in health care expenditure

A fourth key question is how well governments are supporting our health care system in terms of spending. New Zealand escaped the worst of the effects of the 2008 global financial crisis and our governments have continued to increase the funding available to health care (Figure 1).

But we have a growing population and rising prices and simply focusing on total expenditure levels, as governments currently do, does not tell the full picture of how far that spending will go. An analysis of data by the New Zealand Institute of Economic Research and
Victoria University (Figure 2) shows trends in real (inflation-adjusted) health expenditure per capita in New Zealand, clearly demonstrating steady increases during the 2000s but a flatter profile since 2009/10.

Figure 3 shows the percentage increase (or decrease) in real per capita health expenditure year on year, showing a real per capita decline in spending in 2010/11 and 2014/15, and significantly lower overall rates of growth in the 2010s than in earlier years. The data show a lot of variability in increases year on year, something that the sector no doubt 
Figure 3: Year-on-Year Percentage Increase in Real Per Capita Health Expenditure 2000/01-2017/18

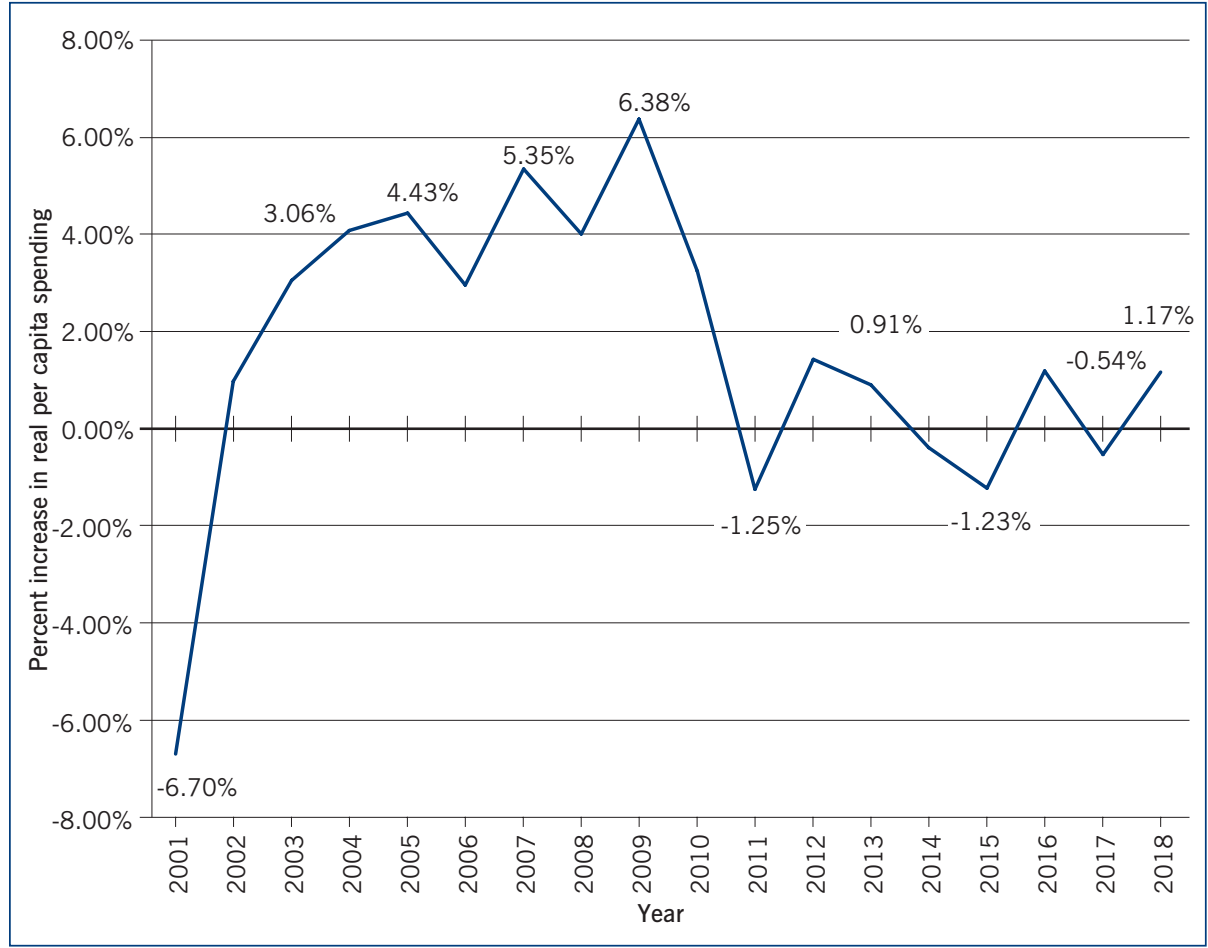

Source: New Zealand Institute of Economic Research and Victoria University, 2017

struggles with in terms of planning, with local peaks often around election years.

Estimates by Infometrics for the New Zealand Labour Party suggest that if cost increases and increases in the population had been fully funded since 2009/10, the sector would have an extra $\$ 2.342$ billion in funding to support health services. That funding, however, must come from somewhere and we need to ask ourselves what we would have been prepared to give up for it to be allocated to health.

A fifth question is how, then, are resources allocated to key priorities within the New Zealand health care sector? Unfortunately, getting a handle on priorities is not straightforward: information on these is not often consolidated in one place. For example, New Zealand currently sets out the following as potential key priorities:

- Better Public Service targets (State Services Commission, 2017);

- health targets (Ministry of Health, 2017b);

- a number of strategies (e.g. the New Zealand Health Strategy (Ministry of Health, 2016a), Healthy Ageing (Associate Minister of Health, 2016));

- a number of plans (e.g. Living Well With Diabetes (Ministry of Health,
2015), Childhood Obesity (Ministry of Health, 2017c));

- specific programmes (e.g. the prime minister's youth mental health project (Ministry of Health, 2017f), bowel cancer screening);

- other general priorities identified in an annual minister's letter of expectations (e.g. improving quality, health technology and workforce) (Ministry of Health, 2017d);

- a new Systems Level Measures performance framework, identifying key targets for district health boards (e.g. reducing ambulatory-sensitive hospitalisations for 0-4-year-olds; reducing amenable mortality; babies in smokefree homes) (Ministry of Health, 2017e).

All the while, district health boards have to 'live within their means': i.e. not overspend their budgets (Ministry of Health, 2017d). There is an urgent need to streamline the processes for signalling on priorities and demonstrate how key priorities and targets and the new Systems Level Measures framework relate to one another and to gains in health.

Tracking expenditure within all these areas is not done in the New Zealand health care system, making it difficult to identify if priority areas are being funded and to what extent. And tracking performance against these priorities - both at national and district health board levels - is also no easy task. There is no one place for New Zealanders to go to clearly see how our health system is performing over time. We also cannot easily tell where we might be getting less service than in the past. And even if there are increases in service delivery in nominal terms, we need to examine the increases in per capita terms, while measures of unmet need, waiting times and other aspects of quality of care are also important in gauging how well our system is doing in meeting needs. A single place where we can go to get an overall sense of the performance of the health system is urgently needed to provide more transparency in health policy.

\section{A closer look at primary health care}

Since 2001 New Zealand has had a Primary Health Care Strategy (King, 2001) which aims to strengthen primary health care services, and deliver services 'closer to home': that is, in community settings such as general practice clinics, with general practitioners, nurses, pharmacists, social workers and allied health professionals increasingly working together to provide more 'integrated' care. A key reason for emphasising primary health care is the growth in the number of New Zealanders living with longer-term conditions that affect their health (such as cancer and diabetes), requiring services that work more closely with people over time and in local settings.

The strategy's overall direction was confirmed through changes of government and ministers, in the form of Better, Sooner, More Convenient in 2007 (Ryall, 2007) and a ministerial review group report in 2009 (Ministerial Review Group, 2009), and most recently in a 'refreshed' New Zealand Health Strategy (Ministry of Health, 2016a, 2016b). The minister of health's most recent letter of expectations for district health boards (2017/18) notes: 'In particular, I want to see a strong focus on providing care in the community and for services to be provided closer to home, especially for the management of long-term conditions' (Ministry of Health, 2017d). 
New money for primary health care to reduce the fees people pay when accessing such services and to extend primary health care services was a feature of the 2000s (Cumming and Mays, 2011; Cumming, Mays and Gribben, 2008). Early research demonstrated some of the developments arising from the Primary Health Care Strategy, including extended services, and an increase in both GP and nurse consultations (Raymont and Cumming, 2013). However, very little research is available examining more recent progress (though see Lovelock et al., 2014). Overall, this means that it remains difficult to determine what progress is being made with respect to primary health care in New Zealand. Here, I focus on several concerns.

First, an enhancement of primary health care services requires New Zealanders to understand the reasons for change, including the increase in longterm conditions that we face and the need for people to take some responsibility for their health and well-being. The distinct roles of primary health care and hospital services need debate and discussion. A cynical public may well view the concept of 'closer to home' as meaning fewer hospital services - and, more specifically, fewer public hospital services - and people having to fall back on their own and family/whānau resources when needing care. Much more attention needs to be given to engaging with New Zealanders on the changes that are occurring in health care.

Second, we would expect a significant increase in the proportion of health care spending going to primary health care services in recent years, given their emphasis in policy. However, analyses undertaken by General Practice New Zealand show this not to be the case. In 2008/09, subsidies to support service user access to first-contact primary health care services sat at $4.51 \%$ of Vote Health; they then fell each year to a low of $4.24 \%$ in 2015/16. General Practice New Zealand estimates an accumulated shortfall of $\$ 139.5 \mathrm{~m}$ over this time for first-contact primary health care services (personal communication). Some increases in funding for very low-cost access-funded practices (practices which get additional funding for keeping fees low) and to support free services for those aged between 6 and 13 have supported primary health care services; but overall General Practice New Zealand finds a total shortfall of $\$ 92.7 \mathrm{~m}$ in funding between 2008/09 and 2015/16.

Third, little new funding has been made available to support further reductions in the fees charged for primary health care services. Consequently, fees for some people are now above the levels in the early 2000s when the Primary Health
$39.3 \%$, with $48.8 \%$ of Māori women signalling issues with access. For those in the least well-off group (quintile 5) the total rate was $35.7 \%$, and for women in that group $42.3 \%$. Inability to obtain care within 24 hours has become the most common reason for lack of access, at $17.5 \%$ of the population, the highest rates being among women aged 35-44 (29.3\%) and Māori women (27.2\%). Unmet need due to cost sits at $14.3 \%$ of the population, with high rates for women aged 25-34 (27.9\%), Māori women at 29.1\%, Pasifika

\section{Although New Zealand is achieving gains in health, further progress is required in key areas. These include reducing unmet need in key areas (such as mental health) and reducing inequities in health.}

Care Strategy was first introduced (Cumming and Gribben, 2007). Ministry of Health data show that in very low-cost access-funded practices, between 2008 and 2017 fees have fallen for those aged 18 and over by just over a dollar per visit, to a weighted average of $\$ 15.47$, ranging from $\$ 0$ to $\$ 18.00$ per visit. This is a bit lower than the averages in 2001 prior to the introduction of the Primary Health Care Strategy. In other practices fees have gone up on average by between $\$ 11.32$ and $\$ 13.45$, around a $40 \%$ increase, and to a weighted average of $\$ 41.85$ per visit, ranging from $\$ 0$ to a high of $\$ 69$ per visit.

Fourth, these fee levels result in alarmingly high rates of unmet need for primary health care. Unmet need is defined here as a person not being able to access care when they felt they needed it within the last 12 months. From recent New Zealand health surveys we can see that, in total, $28.8 \%$ of New Zealanders noted such unmet need, with over $35 \%$ of women aged 25-34, 35-44 and 45-54, Pasifika women and women in quintile 4 (the second most deprived of five quintiles) demonstrating unmet need. For Māori the total rate of unmet need was women at $25.7 \%$ and women in quintile 5 at $24.4 \%$. It is worth noting that the survey asks about at least one occasion on which such unmet need existed. It may well be that some in the population experience the problem multiple times in a year. There are also high rates for unfilled prescriptions for Māori (at 14.9\%) and Pasifika (19.3\%) and those in quintile 5 (12.9\%) compared with the total population at $6.3 \%$.

Fifth, we would expect to find an increase in the number of primary health care consultations, and an increase in the number of consultations with nurses and allied health professionals. According to Ministry of Health data, the total number of GP consultations has gone up by around $1.4 \mathrm{~m}(11.87 \%)$ between 2008 and 2016, while the number of nurse consultations has increased by $1.87 \mathrm{~m}$ (131.94\%). The average number of GP consultations per person per year has increased from 2.9 in $2008 / 09$ to 3 in $2015 / 16$, and the average number of nurse consultations has increased from 0.4 per person per year in $2008 / 09$ to 0.7 in 2015/16. The data also show, however, that higher health need groups (Māori 
and Pasifika peoples, and those on lower incomes) do not have a significantly higher mean number of GP visits (at 3 per annum) and have only a slightly higher mean number of nurse visits $(0.9$ per annum for high needs groups compared with 0.7 for non-high needs groups), suggesting that key barriers to access to primary health care services for these population groups in New Zealand remain a problem. The data also show what happens when fees reduce: those aged between 6 and 13 have had free care since 1 July 2015, and the average total (GP and nurse) consultation rate for those aged $5-14$ has risen by $16.57 \%$ between $2014 / 15$ and 2015/16.

Finally, it is crucial is to understand the overall impact of the new spending that has gone into primary health care services, including whether service users are more satisfied with access and the services they use, how new service delivery is improving health, and health system outcomes: i.e. is it leading to the reductions in hospital service use that we expect? Unfortunately, such analyses are not available in New Zealand, leaving a major gap in our understanding of the impacts of primary health care policy here.

\section{Conclusions}

Although New Zealand is achieving gains in health, further progress is required in key areas. These include reducing unmet need in key areas (such as mental health) and reducing inequities in health. We also need to be better at setting priorities - many new technologies are emerging and we are not going to be able to afford them all. Much clearer information on the performance of the health sector would help us all to judge how the sector is doing. Although New Zealand (like other countries) is emphasising primary health care services, we cannot make significant progress without ensuring that the fees that people pay remain affordable. New Zealand data suggest that funding is not moving to primary health care and that our funding decisions continue to support hospital care. New funding to reduce the fees people pay when they use primary health care services would help encourage New Zealanders to better use such services, but further investigation is needed to understand why services and funding may not be as quickly being moved into primary health care settings. Finally, increased research and evaluation around key policy changes in primary health care are crucial if we are to be sure that the ongoing focus on primary health care is generating the improvements we expect.

\footnotetext{
1 Promoting the independence of people with disabilities is a further goal. Issues relating to disability policy are beyond the
} scope of this article.

\section{References}

Associate Minister of Health (2016) Healthy Ageing Strategy, Wellington: Ministry of Health

Cumming, J. and B. Gribben (2007) Evaluation of the Primary Health Care Strategy: practice data analysis 2001-2005, Wellington: Health Services Research Centre

Cumming, J. and N. Mays (2011) 'New Zealand's primary health care strategy: early effects of the new financing and payment system for general practice and future challenges', Health Economics, Policy and Law, 6 (1), pp.1-21

Cumming, J., N. Mays and B. Gribben (2008) 'Reforming primary health care: is New Zealand's primary health care strategy achieving its early goals?', Australia and New Zealand Health Policy, 5, article 24

Department of Health (1989) New Zealand Health Charter, Wellington: Department of Health

Infometrics (2017) 'Core crown health expenditure since 2009/10 - May 2017', https://d3n8a8pro7vhmx.cloudfront.net/nzlabour/pages/8181/ attachments/original/1496806582/2017_Estimated_Core_Crown_ Health_Expenditure_May_2017.pdf?1496806582

King, A. (2000) The New Zealand Health Strategy, Wellington: Ministry of Health

King, A. (2001) The Primary Health Care Strategy, Wellington: Ministry of Health

Lovelock, K., G. Martin, J. Cumming and R. Gauld (2014) The Evaluation of the Better, Sooner, More Convenient Business Cases in MidCentral and the West Coast District Health Boards, Wellington: Health Research Council of New Zealand and Ministry of Health, retrieved from http://www.victoria.ac.nz/sog/researchcentres/health-servicesresearch-centre/publications/reports/BSMC-Final-Evaluation-Report-23Mar-2015.pdf

Ministerial Review Group (2009) Meeting the Challenge: enhancing sustainability and the patient and consumer experience within the current legislative framework for health and disability services in New
Zealand: report of the Ministerial Review Group, Wellington: Ministerial Review Group, retrieved from http://www.nzdoctor.co.nz/ media/6430/MRG\%20Report\%20Meeting\%20the\%20Challenge.pdf

Ministry of Health (2015) Living Well with Diabetes: a plan for people at high risk of or living with diabetes 2015-2020, Wellington: Ministry of Health, retrieved from http://www.health.govt.nz/system/files/ documents/publications/living-well-with-diabetes-oct15.pdf

Ministry of Health (2016a) New Zealand Health Strategy: future direction: all New Zealanders live well, stay well, get well, Wellington: Ministry of Health

Ministry of Health (2016b) New Zealand Health Strategy: roadmap of actions: all New Zealanders live well, stay well, get well, Wellington: Ministry of Health

Ministry of Health (2017a) Health and Independence Report 2016, Wellington: Ministry of Health

Ministry of Health (2017b) 'Health targets', retrieved from http://www. health.govt.nz/new-zealand-health-system/health-targets

Ministry of Health (2017c) 'Living well with diabetes', retrieved from http:// www.health.govt.nz/our-work/diseases-and-conditions/obesity/ childhood-obesity-plan

Ministry of Health (2017d) 'Minister's 2017/18 letter of expectations', retrieved from http://nsfl.health.govt.nz/dhb-planningpackage/201718-planning-package/supplementary-information201718-planning-guidelines-1

Ministry of Health (2017e) 'Systems level framework', retrieved from http://www.health.govt.nz/new-zealand-health-system/system-levelmeasures-framework

Ministry of Health (2017f) 'Youth mental health project', retrieved from http://www.health.govt.nz/our-work/mental-health-and-addictions/ youth-mental-health-project

New Zealand Institute of Economic Research and Victoria University (2017) 'Budget 2017 analysis of real per person spending shows real 
winners and losers', retrieved from http://www.victoria.ac.nz/ news/2017/05/budget-2017-analysis-of-real-per-person-spendingshows-real-winners-and-losers

OECD (2015) Health At a Glance 2015 - OECD Indicators, Paris: OECD Raymont, A. and J. Cumming (2013) Evaluation of the Primary Health Care Strategy: final report, Wellington: Health Services Research Centre, retrieved from http://www.victoria.ac.nz/sog/researchcentres/ health-services-research-centre/publications/reports

Ryall, H.T. (2007) Better, Sooner, More Convenient: health discussion paper, Wellington: National Party of New Zealand

State Services Commission (2017) 'Better Public Services 2012-2017', retrieved from http://www.ssc.govt.nz/better-public-services
Statistics New Zealand (2015) 'New Zealand period life tables: 2012-14', retrieved from http://www.stats.govt.nz/browse_for_stats/health/life expectancy/NZLifeTables HOTP12-14.aspx

Taylor, L.A., A.X. Tan, C.E. Coyle, C. Ndumele, E. Rogan, M. Canavan, L.A. Curry and E.H. Bradley (2016) 'Leveraging the social determinants of health: what works?', PLOS ONE, 11 (8), e0160217, doi:10.1371/ journal.pone.0160217

World Health Organization (2013) The Economics of the Social Determinants of Health and Health Inequalities: a resource book, Geneva: World Health Organization

\section{SCHOOL OF GOVERNMENT NEW BOOKS}

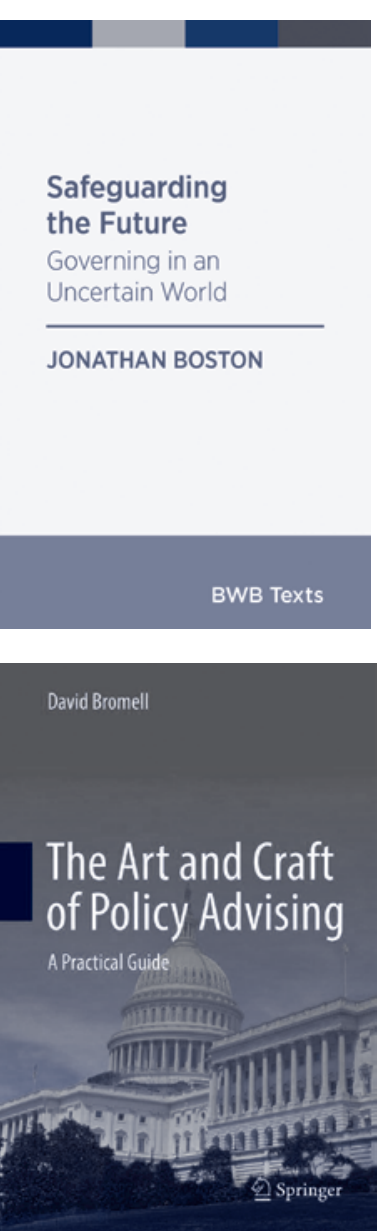

NEW PUBLICATION FROM BRIDGET WILLIAMS BOOKS

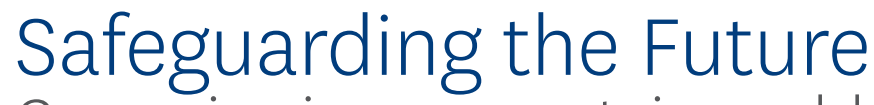

\section{Governing in an uncertain world}

by Jonathan Boston, Victoria University of Wellington

In an era of populist politics, Brexit, Donald Trump, 24- $\quad$ governance' might look like in New Zealand.

hour news cycles and perpetual election campaigning, Confronted with a world becoming more uncertain how do we govern well for the future? How do we by the day, this book is essential reading for anyone take the long view, ensuring that present-day policy questioning how democratic societies can tackle the decisions reflect the needs and safeguard the interests unprecedented challenges ahead.

of future generations?

In this timely BWB Text, acclaimed policy

scholar Jonathan Boston sets out what 'anticipatory

This book can be ordered online from

www.bwb.co.nz/books

\section{NEW PUBLICATION FROM SPRINGER}

\section{The Art and Craft of Policy Advising}

\section{A practical guide by David Bromell}

This book offers a practical guide for policy advisors and their managers, grounded in the author's extensive experience as a senior policy practitioner in central and local government.

The author introduces readers to a public value approach to policy advising that uses collective thinking to address complex policy problems; evidence-informed policy analysis that factors in

emotions and values; and the practice of 'gifting and gaining' (rather than 'trade-offs') in collaborative governing for the long term. Theory is balanced with practical illustrations and processes, tools and techniques, helping readers master the art of communicating what decision-makers need to hear, as well as what they want to hear.

The book can be ordered online from www.springer.com

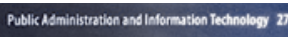

Rowena Cullen Graham Hassall Editors

\section{Achieving} Sustainable E-Government in Pacific Island States

\section{NEW PUBLICATION FROM SPRINGER}

\section{Achieving Sustainable E-Government in Pacific Island States}

Editors Rowena Cullen and Graham Hassall, Victoria University of Wellington

This book analyses the common set of obstacles to the development and integration of government Information and Communication Technology (ICT) projects and effective e-government initiatives in developing countries. It draws on the expertise and experience of more developed states in the Pacific, notably Australia and New Zealand, both highly rated in global rankings for e-government and active in a variety of e-government development projects across the region.

The book can be ordered online from www.springer.com 